\title{
Indigenous Education in Comparative Perspective: Global Opportunities for Reimagining Schools
}

\author{
Michael Cottrell \\ Department of Educational Administration, University of Saskatchewan, Canada
}

\begin{abstract}
Despite the striking parallels in the educational experiences of Indigenous peoples in Canada, the United States, Australia and New Zealand, very little research of an explicitly comparative nature has actually been conducted. These modern states are all are products of European colonizing projects which marginalized Indigenous peoples, and currently members of Indigenous groups are among the most disadvantaged in terms of educational outcomes in all four jurisdictions. Closing the educational achievement gap between Indigenous and nonIndigenous learners is, consequently, a shared and urgent policy priority. While the uniqueness and diversity of Indigenous groups militate against any simple application of global solutions to local circumstances, each country has much to learn from initiatives, both successful and unsuccessful, which have been developed in other jurisdictions. From a macro-analytical level it appears that educators in all four jurisdictions are moving away from deficit approaches and embracing cultural congruence and evidence based-practice as theoretical underpinnings for educational policy with respect to Indigenous students. Recent national, state and provincial-level initiatives have typically been informed by cultural congruence theory, by the School Effectiveness and School Improvement movements and by insights from research around "schools in challenging circumstances". The discourse of post-colonialism is exerting an increasingly powerful influence on educational policy in all four countries and serves as a strategy of state legitimation by liberal democracies to foster social cohesion. In all four jurisdictions publiclyfunded schools are seen as the institutions with the greatest capacity to foster shared understanding and respect among different cultural groups and remain possibly the best hope for forging harmonious and prosperous futures in these increasingly diverse and globalized societies.
\end{abstract}

\section{Introduction}

Given the striking similarities between the histories and current circumstances of Indigenous peoples in Canada, the United States, Australia and New Zealand, the educational experiences of these four groups provide a particularly appropriate focus for comparative inquiry. These modern states are all are products of European colonizing projects which marginalized Indigenous peoples, and currently members of Indigenous groups are among the most disadvantaged in terms of educational outcomes in all four jurisdictions. Closing the educational achievement gap between Indigenous and nonIndigenous learners is, consequently, a shared and urgent policy priority. This transnational odyssey to achieve Indigenous educational parity is driven by a variety of motives, including the very significant implications of demographic trajectories for social justice, labor market participation, economic sustainability, cross-cultural harmony and social cohesion. It is also the result of a postcolonial struggle by Indigenous peoples to reassert control over their children's education and to see their cultures and epistemologies reflected in public educational institutions, curriculum and discourse.

Here I provide a brief historical background and trace the broad contours of policy discourse around Indigenous education in all four countries to identify and assess the critical learning conditions within schools and family/community settings which are deemed most effective in enhancing educational outcomes for Indigenous students. Since identifying and sharing the features of effective policies, programs and practices are essential if gains are to be generated on a larger scale, I am hopeful that these findings will be of practical benefit to Aboriginal students and communities and to the educators and systems which serve them in a variety of regional, national and international school settings.

A documentary inquiry focusing on official reports and academic and applied research on Indigenous education in the four countries, employing deductive, historical and discursive analysis is the main method of data collection. I conceptualize the nature of policy development and change in Indigenous education by applying a multidisciplinary approach to social theory and critical race theory by Delgado and Stefanic [23] to illuminate the complex interactions between Indigenous peoples and these four nation states 
within which the dynamics of educational disadvantage operate.

\section{Historical Overview}

Indigenous people in Canada, the United States, Australia and New Zealand share a problematic past. Historically they were positioned as the 'other' by a larger Eurocentric modernization and colonization enterprise which sought to relegate Indigenous peoples globally to invisibility and backwardness [26], [42]. In campaigns which had parallels in all four settler societies education was a formidable weapon wielded by Christian Churches and neoEuropean settler states against Indigenous communities and families for the purpose of cultural transformation and assimilation [2], [42], [47]. This attachment to the idea of education as a key tool in the racial transformation of Indigenous peoples found particularly graphic expression in mission, residential, boarding or industrial schools which operated in most of these countries between the 1870's and the 1980's [2]. The denial of Indigenous distinctiveness, the removal of children from families, the severing of links between culture and spirituality and the erosion of epistemic and sociolinguistic traditions have all had profoundly negative long-term intergenerational consequences [1], [8], [9], [15]. At best, the construction of schools as assimilative instruments limited Indigenous parental involvement in schools for multiple generations. At worst, many Indigenous parents still harbour lingering suspicions of schools as abusive sites. As a consequence of this alienation, Indigenous people are frequently less than enthusiastic about their or their children's involvement in mainstream education [1], [24], [36]. This is a common experience shared by many colonized Indigenous groups and Australian researchers, in particular, have focused on resistance theory to understand this phenomenon and its contemporary implications for public schools. Overcoming that deep-seated historical suspicion is widely regarded as both a formidable challenge and as key to improving educational outcomes for Indigenous students locally and globally [30], [49].

While sustained historical efforts to eradicate Indigenous peoples as distinct cultural groups inflicted significant damage on their cultures, languages and family structures, they failed to realize the primary policy objective of rendering Indigenous people into a vanishing race [8]. Demographic developments since the 1950's have witnessed a remarkable reversal of previous population decline, with the result that Indigenous peoples now constitute the youngest and fastest growing segments of populations in many regions across these four countries. Indigenous demographic recovery has been accompanied by a decolonization project based on a discourse of indigeneity [41]. At its most fundamental this is articulated by Indigenous leaders as an attachment to ancestral territories, a determination to preserve sovereignty within those territories and a commitment to transmit cultural, linguistic and spiritual distinctiveness to future generations as the basis for continued existence as separate peoples [41], [43]. This development might best be understood as emanating from tensions within modernity caused by globalization, including a "fundamental contradiction between a seemingly irresistible modernity and past legacies that not only refuse to go away, but draw renewed vitality from the very globalizing process". A critical part of this decolonization program is a repudiation of the legacies of Eurocentric education and a demand to bring into modernity the voices and epistemologies of those whom Eurocentric colonialism sought to render invisible [26].

Although impressive progress has been made by Indigenous people over the past generation, widespread and systemic disadvantage is still too often the norm across all four countries. Collectively Indigenous peoples experience deprivation, unemployment, poverty, crowding, welfaredependency, incarceration, suicide, ill health and premature mortality at rates far higher than the dominant Caucasian population [19]. Research has established a close and causal connection between education, employment, health and other measures of wellbeing, suggesting that schooling is a vital point of intervention [14], [44].

\section{Literature Review}

Despite the striking parallels in the educational experiences of Indigenous peoples in these four countries, very little research of an explicitly comparative nature has actually been conducted. This limited transnational perspective is especially surprising given the fact that Indigenous peoples and educational establishments in all four jurisdictions share strikingly similar histories and face many similar challenges. Cook et al.'s survey of wellbeing identified gradual improvements in educational outcomes among Indigenous peoples in these four countries over the past decade but they noted that this progress did not keep pace with rising achievements among non-Indigenous people in Australia and New Zealand [19]. An overview of Australian, Canadian, and American policy concluded that Australia has "the worst Indigenous educational outcomes of any comparable Western settler society" [30], [14]. Fitzgerald's comparison of Indigenous female school administrators in Canada, Australia and New Zealand identified an emerging global desire in postcolonial societies to devise ways that traditional Indigenous beliefs and values might inform models of school leadership and governance [28]. Hickling-Hudson and Ahlquist's 
comparison of curriculum in Australia and the U.S. suggested that practices dominated by the privileges of whiteness are still prevalent [34]. These studies, situated within a comparative framework, point to the benefits of researchers adopting a global perspective in response to local challenges and opportunities.

\section{Contribution to Knowledge}

The uniqueness and diversity of Indigenous groups militate against any simple application of global solutions to local circumstances. Nevertheless, it is evident that each country has much to learn from initiatives, both successful and unsuccessful, which have been developed in other jurisdictions. A logical approach would be to build on selected initiatives which clearly are showing good results and extend them transnationally, and to abandon strategies, however attractive or expedient, which are proving unsuccessful. From a macro-analytical level it appears that educators in all four jurisdictions are moving away from deficit approaches and embracing cultural congruence and evidence based-practice as theoretical underpinnings for educational policy with respect to Indigenous students. Recent national, state and provincial-level initiatives have typically been informed by cultural congruence theory, by the School Effectiveness and School Improvement movements and by insights from research around "schools in challenging circumstances" [25], [27], [32], [37], [44]. Specific practices which emerge from these insights include the adoption of transformative models of school leadership [28], [29], [31]; the provision of enhanced early learning opportunities and meaningful partnerships with parents [22], [46]; the delivery of culturally responsive instruction by culturally alike, "personcentred" teachers [16]; ensuring adequate time for learning 40]; ensuring smaller class sizes catering to heterogeneous student groupings based on the Community School model [38] and creating models of governance where Indigenous communities have meaningful control over their children's education [9].

The discourse of post-colonialism, defined as a strategy of reconciliation between Indigenous groups and the immigrant or settler majority and their descendants against a backdrop of multiculturalism, is exerting an increasingly powerful influence on educational policy in all four countries [35], [48]. Expressed as formal recognition and official apology for past injustices, often through public commissions and recognition of special rights for Indigenous minorities in postcolonial nation-states, this frequently serves as a strategy of legitimation employed by liberal democracies to foster social cohesion [41]. In all four jurisdictions publiclyfunded schools are seen as the institutions with the greatest capacity to foster shared understanding and respect among different cultural groups and remain possibly the best hope for forging harmonious and prosperous futures in these increasingly diverse and globalized societies [21], [34], [35], [48].

\section{Conclusion}

From this brief sketch it is obvious that a comparative perspective has the potential to be of enormous assistance to policymakers, academic researchers, and classroom teachers involved in Indigenous education. At the very least it provides a welcome corrective to the tendency in much of the national educational research literature to problematize Indigenous students, families, and communities. The global search for improved Indigenous education outcomes, in conjunction with the postcolonial turn in education, is an opportunity to fundamentally re-imagine how schools are constructed and operated and to reconfigure how schools relate to learners, their families, and their communities. Simultaneously it presents a unique opportunity for educators to "confront their epistemic and ontological assumptions about teaching and learning [and challenge] the established curriculum practices and interests that have been traditionally exercised in public schools" (Cherubini, [18]). It is evident that undertaking this transformation will require embracing substantially greater change than can be made "comfortably or easily" [39]. However, in addition to pursuing an unequivocally moral purpose, I am also convinced that the rewards will be commensurate with the effort.

\section{References}

[1] Agbo, S. A., (2007). Addressing school-community relations in a cross-cultural context: A collaborative action to bridge the gap between First Nations and the school. Journal of Research in Rural Education 22(8) 1-14.

[2] Armitage, A. (1995). Comparing the policy of Aboriginal assimilation: Australia, Canada and New Zealand. Vancouver, BC: UBC Press.

[3] Audas, R. \& Willms, D. (2001). Engagement and dropping out of school: A life-course perspective. Ottawa, ON: Human Resources Development Canada, Applied Research Branch. Retrieved from www.hrdcdrhc.gc.ca/sp-ps/arbdgra/publications/research/investing.shtml.

[4] Armitage, A. (1995). Comparing the policy of Aboriginal assimilation: Australia, Canada and New Zealand. Vancouver, BC: UBC Press.

[5] Alexander, K. L., Entwistle, D. R., \& Bedinger, S. D. (1994). When expectations work: Race, socioeconomic 
differences in school performance. Social Psychology Quarterly, 57(4), 283-299.

[6] Ball, J., \& Simpkins, M. (2004). The community within the child. American Indian Quarterly, 28(3/4), 480-498.

[7] Ball, J., \& Pence, A. (2005). Supporting Indigenous children's development: Community-university partnerships. Vancouver, BC: UBC Press.

[8] Barnes, R., Josefitz, N., \& Cole, E. (2006) Residential Schools: Impact on Aboriginal students academic and cognitive development Canadian Journal of School Pychology 21 (1-2), 18-32.

[9] Battiste, M. (2005, November). State of Aboriginal learning: Background paper for the "National Dialogue on Aboriginal Learning." Ottawa, ON: Canadian Council on Learning. Retrieved from http://www.cclcca.ca/NR/rdonlyres/210AC17C-A357-4E8D-ACD4B1FF498E6067/0/StateOfAboriginalLearning.pdf

[10] Bell, D. (2004). Sharing our success: Ten case studies of Aboriginal schooling. Kelowna, BC: Society for the Advancement of Excellence in Education.

[11] Beresord, Q., \& Gray, J. (2006). Models of policy development in Aboriginal education: issues and discourse. Australian Journal of Education, 50(3), 265-280.

[12] Bishop, R., Berryman, M., Cavanagh, T., \& Teddy, L. (2007). Te Kotahitanga Phase 3 Whanaugatanga: Establishing a culturally responsive pedagogy of relations in mainstream secondary school classrooms. Report to Ministry of Education, NZ.

[13] Bishop, R., Berryman, M., \& Richardson, C. (2002) Te Toi Huarewa: Effective teaching and learning in total immersion Maori language educational settings. Canadian Journal of Native Education, 26(1), 44-61.

[14] Bradley, S., Draca, M., Green, C., \& Leeves, G. (2007). The magnitude of educational disadvantage of indigenous minority groups in Australia. Journal of Population Economics, 20(3), 547-569.

[15]Cappon, P. (2008). Measuring success in First Nations, Inuit, and Métis learning. Ottawa, ON: Canadian Council on Learning. Retrieved from http://ccl-

cca/NR/rdonlyres/ODOA5F71191-43D9-A46013D7C9BECAB/0/Cappon_PolicyOptions.pdf

[16] Castagno, A. E., \& Brayboy, A. M., (2008). Culturally responsive schooling for Indigenous.

[17] Youth: A review of the Literature. Review of Educational Research, 78(4), 941-993.

[18] Cherubini, L. (2009). "Taking Haig-Brown seriously": Implications of Indigenous thought on Ontario educators. Journal of the Canadian Association for Curriculum Studies, 7(1), 6 -23.

[19] Cook, M., Mitrou, F., Lawrence, D., Guimond, E., \& Beavon, D. (2007). Aboriginal wellbeing. in four countries: An application of the UNDP'S Human Development Index to Aboriginal Peoples in Australia, Canada, New Zealand, and the United States. BMC International Health and Human Rights, 7(9), 1-39.

[20] Cottrell, M., Preston, J., Pearce, J. \& Pelletier, T. (2009) Significant leadership and ethical space: Transforming educational opportunities for First Nations and Métis learners in Saskatchewan. Saskatoon, SK: Saskatchewan Educational Leadership Unit (SELU).

[21] de Costa, J., \& Bell, S. (2001, April). A comparison of literacy effects of full day vs. half-day kindergarten. Paper presented at the Annual Meeting of the American Educational Research Association, Seattle, WA. (ERIC Document Reproduction Service No. ED451938).

[22] Delgado \& Stefanic, (2001). Critical race theory: An introduction. New York: New York, University Press.

[23] Deloria, V. \& Wildcat, (2001). Power and place: Indian education in America. Golden, CO: Fulcrum Resources.

[24] Demmert, W. (2001). Improving academic performance among Native American students: A review of the literature. Charlston, WV: ERIC Clearinghouse on Rural Education and Small Schools.

[25] Dirlik, A. (2003). Global modernity? Modernity in an age of global capitalism. European Journal of Social Theory, 6(3), 275-292.

[26] Department of Education, Science and Training. (2004). Working together for Indigenous youth: A national framework. Canberra, ACT: Commonwealth of Australia.

[27] Fitzgerald, T. (2006). Walking between two worlds. Indigenous women and educational leadership. Educational Management Administration and Leadership, 34(2), 201-213.

[28] Fullan, M. (2005). Leadership \& sustainability: System thinkers in action. Thousand Oaks, CA: Corwin.

[29] Gray, J., \& Bereford, Q. (2008). A “formidable challenge:” Australia's quest for equity in Indigenous education. Australian Journal of Education, 52(2), 197227.

[30] Hargreaves, A. (2009). The fourth way of change: Towards an age of inspiration and sustainability. In A. Hargreaves \& M. Fullan (Eds.), Change wars (pp.11-43). Bloomington IN: Solution Tree.

[31] Harker, R. (2007). Ethnicity and school achievement in New Zealand: Some data to supplement the Biddulph et al. (2003) best evidence synthesis: Secondary analysis of the Progress at School and Smithfield datasets for the iterative Best Evidence Synthesis Programme. Wellington, NZ: Ministry of Education.

[32] Harker, R. (2007). Ethnicity and school achievement in New Zealand: Some data to supplement the Biddulph et al. (2003) best evidence synthesis: Secondary analysis of the Progress at School and Smithfield datasets for the 
iterative Best Evidence Synthesis Programme. Wellington, NZ: Ministry of Education.

[33] Hickling-Hudson \& Ahlquist, (2003) Contesting the curriculum in the schooling of Indigenous children in Australia and the United States: From Eurocentrism to culturally powerful pedagogies. Comparative Education Review, 47(1), 62-81.

[34] Hickling-Hudson, A. (2003a). Multicultural Education and the Postcolonial Turn. Policy Futures in Education, 1(2), 381-401.

[35] Ing, R. (2000). Dealing with shame and unresolved trauma: residential school and its impact on second and third generation adults Ph.D. dissertation, UBC).

[36] Larson, J. C. (2003). Reducing the school performance gap among socioeconomically diverse schools. Rockville, MD: Montgomery County Public Schools. Retrieved from:

http://www.montgomeryschoolsmd.org/info/CTBS2003/P DF/2003CTBSFull-DayKinderStudy.pdf

[37] Levin, B. (2004). Students at risk: A review of research. Paper prepared for The Learning Partnership, Toronto. Available at www.thelearningpartnership.ca.

[38] Leithwood, K., (2009). Critical learning conditions for improvements in schools serving First Nations and Métis children. Significant Leadership and Ethical Space: Transforming Educational Opportunities for First Nations and Métis Learners in Saskatchewan, pp. 77-101. A Report to the Saskatchewan Ministry of Education, First Nations and Métis Branch, Saskatchewan Educational Leadership Unit, Department of Educational Administration University of Saskatchewan, Saskatoon, Sk.

[39] Leithwood, K., \& Jantzi, D. (2005). Tranformational school leadership for large-scale reform; Effect on students, teachers, and their classroom practices. School Effectiveness and School Improvement , 17(2), 201-227.

[40] Merlan, F. (2009). Indigeneity, global and local. Current Anthropology, 50(3), 303-333.

[41] Milloy, J. (1999). A national crime: The Canadian government and the residential school system: 1879 to 1986. Winnipeg, MB: University of Manitoba Press.

[42] Muehlebach, A. (2003). What self in self-determination? Notes from the frontiers of transnational indigenous activism. Identities: Global Studies in Culture and Power 10(2), 241-268.

[43] Ontario Ministry of Education. (2007). Ontario First Nation, Métis, and Inuit education policy Framework. Ottawa, ON: Author.

[44] O’Rourke, V., Craven, R., \& Seeshing-Young, A. (2008). Closing the Educational gap for Aboiriginal primary students in low density schools: A multi-method longitudal analysis elucidating impact of inclusive practices. Paper presented to the Australian Association for Research in Education, Brisbane, AU.
[45] Preston, J., P., Cottrell, M., Pelletier, T., R., \& Pearce, J., V. (2010). Aboriginal early childhood education in Canada: Issues of context. Journal of Early Child Research.

[46] Reynolds, H. (2001). An indelible stain? The question of genocide in Australia’s history Ringwood: Victoria, Penguin.

[47] Short, D. (2005) Reconciliation and the problem of internal colonialism. Journal of Intercultural Studies, 26(3), 267-282.

[48] Silver, J., Mallett, K., Greene, J. \& Simard, F. (2002). Aboriginal education in Winnipeg inner city high schools. Winnipeg, MB: Canadian Centre for Policy Alternatives. Retrieved from http://www.policyalternatives.ca/documents/Manitoba_Pu bs/aborignal_education.pdf. 